\title{
Finite-Time Synchronization of Chaotic Systems with Different Dimension and Secure Communication
}

\author{
Shouquan Pang, Yu Feng, and Yongjian Liu \\ Guangxi Colleges and Universities Key Laboratory of Complex System Optimization and Big Data Processing,
} Yulin Normal University, Yulin 537000, China

Correspondence should be addressed to Yongjian Liu; liuyongjianmaths@126.com

Received 8 May 2016; Accepted 12 July 2016

Academic Editor: Ricardo Aguilar-López

Copyright (C) 2016 Shouquan Pang et al. This is an open access article distributed under the Creative Commons Attribution License, which permits unrestricted use, distribution, and reproduction in any medium, provided the original work is properly cited.

\begin{abstract}
Finite-time synchronization of chaotic systems with different dimension and secure communication is investigated. It is rigorously proven that global finite-time synchronization can be achieved between three-dimension Lorenz chaotic system and fourdimension Lorenz hyperchaotic system which have certain parameters or uncertain parameters. The electronic circuits of finite-time synchronization using Multisim 12 are designed to verify our conclusion. And the application to the secure communications is also analyzed and discussed.
\end{abstract}

\section{Introduction}

Synchronization of chaotic systems recently has become one of the most interesting topics because of the seminal work of Pecora and Carroll [1]. These phenomena have arisen in various fields of science, like engineering technology [2], ecological system [3], biological neurons [4], and others [5-8] various types of synchronization. They have been deeply investigated in the previous literature. A large number of results have been reported in the past two decades [9].

From a practical point of view, it will be more reasonable to realize synchronization in a given time [10-13]. This means optimality in convergence time [14]. This problem is important in all fields where synchronization finds or will find practical interest [15-17]. If we consider, for example, the application of synchronization in secure communications, the range of time during which the chaotic oscillators are not synchronized corresponds to the range of time during which the encoded message can unfortunately not be recovered or sent. More than a grave and irreversible loss of information, this is a catastrophe in digital telecommunications, since the first bits of standardized bit strings always contain signalization data, that is, the "identity card" of the message. Hence, it clearly appears that the synchronization time has to be minimized, so that the chaotic oscillators synchronize as fast as possible. In this context, it is fair to say that there is a need to study finite-time chaos synchronization and optimization problems of nonlinear systems with uncertainties.

This paper mainly addresses the problem of finitetime master-slave synchronization of the three-dimensional (3D) Lorenz system and four-dimensional (4D) hyperchaotic Lorenz system. A family of feedbacks has been proposed to achieve the finite-time synchronization of the two systems with different dimension. It is rigorously proven that global finite-time synchronization can be achieved between three-dimension Lorenz chaotic system and four-dimension Lorenz hyperchaotic system which have certain parameters or uncertain parameters. Finally, the experimental setup for the coupling process has also been designed via Multisim 12 simulations. The numerical simulation and circuit experiment show that the proposed control technique is feasible and reliable.

\section{Preliminary Definitions and Lemma}

Finite-time synchronization means that the state of the slave system can track the state of the master system after the finite 
time. The definition of finite-time synchronization is given as follows:

$$
\begin{aligned}
& \dot{x}(t)=f(t, x), \\
& \dot{y}(t)=g(t, y)+u(t, x, y),
\end{aligned}
$$

where $x(t)$ and $y(t)$ are two $N$-dimensional state vectors. $x, y \in R^{n}, f$, and $g$ are differentiable functions in $R \times$ $R^{n} \rightarrow R^{n}$. If there exists a constant $t_{s}>0$, such that $\lim _{t \rightarrow t_{s}}\|e\|=\lim _{t \rightarrow t_{s}}\|y(t)-x(t)\|=0$, one says that when $t>t_{s}$, synchronization of the $\dot{x}(t)=f(t, x)$ and $\dot{y}(t)=$ $g(t, y)+u(t, x, y)$ is achieved in a finite time.

Lemma 1. Let the nonlinear system

$$
\begin{aligned}
& \dot{z}(t)=-k \cdot \operatorname{sgn}(z)|z|^{m}, \\
& z(0)=z_{0},
\end{aligned}
$$

where $k>0,0<m<1$. For any initial value $z(0)$, system (2) is stable in finite time $t_{s}=\left|z_{0}\right|^{1-m} / k(1-m)$.

\section{Finite-Time Synchronization of Different Dimension Systems}

Lorenz system is considered a paradigm, since it captures many of the feathers of chaotic dynamics. The Lorenz system is described by the following nonlinear equations:

$$
\begin{aligned}
& \dot{x}_{1}(t)=a\left(x_{2}(t)-x_{1}(t)\right), \\
& \dot{x}_{2}(t)=c x_{1}(t)-x_{2}(t)-x_{1}(t) x_{3}(t), \\
& \dot{x}_{3}(t)=x_{1}(t) x_{2}(t)-b x_{3}(t),
\end{aligned}
$$

where $a, b$, and $c$ are the constants. With $a=10, b=8 / 3$, and $c=28$, the Lorenz system shows chaotic behavior.

By introducing a nonlinear feedback controller to the second equation of the system (3), the follow hyperchaotic system is obtained [18]:

$$
\begin{aligned}
& \dot{y}_{1}(t)=\alpha\left(y_{2}(t)-y_{1}(t)\right), \\
& \dot{y}_{2}(t)=\gamma y_{1}(t)-y_{2}(t)-y_{2}(t) y_{3}(t)+y_{4}(t), \\
& \dot{y}_{3}(t)=-\beta y_{3}(t)+y_{1}(t) y_{2}(t), \\
& \dot{y}_{4}(t)=-k y_{1}(t)-0.3 y_{2}(t) y_{3}(t) .
\end{aligned}
$$

When $k=2, \alpha=10, \beta=8 / 3$, and $\gamma=28$, the four Lyapunov exponents are $\lambda_{1}=0.2230, \lambda_{2}=0.1389, \lambda_{3}=0$, and $\lambda_{4}=-14.0380$. The Lyapunov dimension is $D_{L}=3.0258$, and numerical simulations have verified that system (4) indeed has a hyperchaotic attractor.

3.1. Finite-Time Synchronization of Systems with the Certain Parameters. This subsection deals with finite-time synchronization of Lorenz system and hyperchaotic Lorenz system. Considering any initial conditions, system (3) is regarded as the master and system (4) as the slaver.
The master system

$$
\dot{X}=\left(\begin{array}{ccc}
-a & 1 & 0 \\
c & -1 & 0 \\
0 & 0 & -b
\end{array}\right) X+\left(\begin{array}{c}
0 \\
-x_{1} x_{3} \\
x_{1} x_{2}
\end{array}\right)
$$

could be described by

$$
\dot{X}=A X+F(x) \text {, }
$$

where $X=\left(\begin{array}{l}x_{1} \\ x_{2} \\ x_{3}\end{array}\right), A=\left(\begin{array}{ccc}-a & 1 & 0 \\ c & -1 & 0 \\ 0 & 0 & -b\end{array}\right), F(x)=\left(\begin{array}{c}0 \\ -x_{1} x_{3} \\ x_{1} x_{2}\end{array}\right)$, and $x_{1}, x_{2}$, and $x_{3}$ are the state constants and $a, b$, and $c$ are state parameters of system.

Hyperchaotic Lorenz system (4) is regarded as the slaver system, and $u(e, y)$ is controllers, which is determined for achieving synchronization between master system (3) and slaver system (4). Described by

$$
\dot{Y}=B Y+g(y)+u(e, y)
$$

where $Y=\left(y_{1}, y_{2}, y_{3}, y_{4}\right)^{T}$ is the state vector of the responder system, $g(y)=\left(0,-y_{1} y_{3}, y_{1} y_{2},-0.3 y_{2} y_{3}\right)^{T}$ is a continuous smooth function and $u=\left(u_{1}, u_{2}, u_{3}, u_{4}\right)^{T}$ is a control function. To make the same structures between (6) and (7), a new artificial variable $x_{4}$ is introduced into system (6) and set $\dot{x}_{4}(t)=0$. Subtract (6) from (7) and define the state errors as

$$
\begin{aligned}
& e_{1}=y_{1}-x_{1}, \\
& e_{2}=y_{2}-x_{2}, \\
& e_{3}=y_{3}-x_{3}, \\
& e_{4}=y_{4}-x_{4} .
\end{aligned}
$$

Then the error system between the Lorenz system and the controlled hyperchaotic Lorenz system could be written as

$$
\begin{aligned}
& \dot{e}_{1}=a\left(e_{2}-e_{1}\right)+u_{1}, \\
& \dot{e}_{2}=c e_{1}-e_{2}-e_{1} e_{3}-e_{1} x_{3}-e_{3} x_{1}+u_{2}, \\
& \dot{e}_{3}=b e_{3}+e_{1} e_{2}+e_{1} x_{2}+e_{2} x_{1}+u_{3}, \\
& \dot{e}_{4}=-2 e_{1}-2 x_{1}-e_{2} e_{3}-e_{2} x_{3}-e_{3} x_{2}-x_{2} x_{3}+u_{4} .
\end{aligned}
$$

The above four equations merge into a unified form:

$$
\dot{e}=B e+f(e, x)+u(e, x),
$$


where

$$
\begin{aligned}
& e=\left(\begin{array}{l}
e_{1} \\
e_{2} \\
e_{3} \\
e_{4}
\end{array}\right), \\
& B=\left(\begin{array}{cccc}
-a & a & 0 & 0 \\
c & -1 & 0 & 0 \\
0 & 0 & b & 0 \\
-2 & 0 & 0 & 0
\end{array}\right),
\end{aligned}
$$$$
f(e, x)
$$

$$
\begin{gathered}
=\left(\begin{array}{c}
-x_{3} e_{2}-x_{2} e_{3}-e_{2} e_{3} \\
x_{3} e_{1}+x_{1} e_{3}+e_{1} e_{3} \\
\frac{1}{3} x_{2} e_{1}+\frac{1}{3} x_{1} e_{2}+\frac{1}{3} e_{1} e_{2} \\
0.5 x_{2} e_{3}+0.5 e_{2} e_{3}+d x_{1}+0.5 x_{2} x_{3}
\end{array}\right), \\
u=\left(\begin{array}{c}
u_{1} \\
u_{2} \\
u_{3} \\
u_{4}
\end{array}\right) .
\end{gathered}
$$

Our aim is to design a suitable controller, in which we can achieve the finite-time synchronization of Lorenz system (3) and hyperchaotic Lorenz system (4). This problem can be converted to design a controller to attain finite-time stability of error system (10).

For Lorenz system (3) and hyperchaotic Lorenz system (4) define the control functions $u_{1}, u_{2}, u_{3}$, and $u_{4}$ as follows:

$$
\begin{aligned}
u_{1}= & -a\left(e_{2}-e_{1}\right)-k \operatorname{sgn}\left(e_{1}\right)\left|e_{1}\right|^{m}, \\
u_{2}= & -c e_{1}+e_{2}+e_{1} e_{3}+e_{1} x_{3}+e_{3} x_{1} \\
& -k \operatorname{sgn}\left(e_{2}\right)\left|e_{2}\right|^{m}, \\
u_{3}= & -b e_{3}-e_{1} e_{2}-e_{1} x_{2}-e_{2} x_{1}-k \operatorname{sgn}\left(e_{3}\right)\left|e_{3}\right|^{m}, \\
u_{4}= & 2 e_{1}+2 x_{1}+0.3 e_{2} e_{3}+0.3 e_{2} x_{3}+0.3 e_{3} x_{2} \\
& +0.3 x_{2} x_{3}-k \operatorname{sgn}\left(e_{4}\right)\left|e_{4}\right|^{m},
\end{aligned}
$$

where $k>0,0<m<1$. Substituting (12) into (10) yields

$$
\dot{e}=\left(\begin{array}{c}
-k \operatorname{sgn}\left(e_{1}\right)\left|e_{1}\right|^{m} \\
-k \operatorname{sgn}\left(e_{2}\right)\left|e_{2}\right|^{m} \\
-k \operatorname{sgn}\left(e_{3}\right)\left|e_{3}\right|^{m} \\
-k \operatorname{sgn}\left(e_{4}\right)\left|e_{4}\right|^{m}
\end{array}\right) \text {. }
$$

From Lemma 1, system (13) is stable in the finite time. That means

$$
\begin{aligned}
t & >t_{s i}=\frac{\left|e_{0 i}\right|^{1-m}}{k(1-m)}, \\
e_{i}\left(t_{i s}\right) & =0
\end{aligned}
$$

$$
(i=1,2,3,4)
$$

The synchronization of Lorenz system (3) and hyperchaotic Lorenz system (4) is achieved in a finite time.

Theorem 2. Suppose that $k>0,0<m<1$. Let controller $u_{i}(i=1,2,3,4)$ be defined as (12). Then error system (10) can be stabilized in finite time by the controller $u_{i}(i=1,2,3,4)$. That is to say, slave system (4) will synchronize with master system (3) in finite time.

3.2. Finite-Time Synchronization of Systems with Uncertain Parameters. We consider the more realistic and practical case, where some of the parameters of the master system and slave system are unknown. It is valuable because practical chaos systems are often disturbed by different factors. It is that the parameters of the systems have been disturbed.

Consider the master system

$$
\begin{aligned}
& \dot{x}_{1}(t)=a\left(x_{2}(t)-x_{1}(t)\right), \\
& \dot{x}_{2}(t)=\left(c+\Delta_{1}\right) x_{1}(t)-x_{2}(t)-x_{1}(t) x_{3}(t), \\
& \dot{x}_{3}(t)=x_{1}(t) x_{2}(t)-\left(b+\Delta_{2}\right) x_{3}(t)
\end{aligned}
$$

and the slave system

$$
\begin{aligned}
\dot{y}_{1}(t)= & \alpha\left(y_{2}(t)-y_{1}(t)\right)+V_{1}(t), \\
\dot{y}_{2}(t)= & \left(\gamma+\Delta_{3}\right) y_{1}(t)-y_{2}(t)-y_{1}(t) y_{3}(t)+y_{4}(t) \\
& +V_{2}(t), \\
\dot{y}_{3}(t)= & -\left(\beta+\Delta_{4}\right) y_{3}(t)+y_{1}(t) y_{2}(t)+V_{3}(t), \\
\dot{y}_{4}(t)= & -k y_{1}(t)-0.3 y_{2}(t) y_{3}(t)+V_{4}(t),
\end{aligned}
$$

where $\Delta_{i}(i=1,2,3,4)$ are the increments of the parameter, which is caused by the interruption, and $V_{1}(t), V_{2}(t), V_{3}(t)$, and $V_{4}(t)$ are the control functions. Analogously, as in Section 3.1, a new artificial variable $x_{4}$ is given and $\dot{x}_{4}(t)=0$, by defining the synchronization error in the following way:

$$
\begin{aligned}
& e_{1}=y_{1}-x_{1}, \\
& e_{2}=y_{2}-x_{2}, \\
& e_{3}=y_{3}-x_{3}, \\
& e_{4}=y_{4}-x_{4},
\end{aligned}
$$


and then the error system can be written as

$$
\begin{aligned}
\dot{e}_{1}= & \alpha\left(e_{2}-e_{1}\right)+(\alpha-a)\left(x_{2}-x_{1}\right)+V_{1}, \\
\dot{e}_{2}= & \left(\gamma+\Delta_{3}\right) e_{1}+\left(\gamma+\Delta_{3}-c-\Delta_{1}\right) x_{1}-e_{2}-e_{1} e_{3} \\
& -e_{1} x_{3}-x_{1} e_{3}+y_{4}+V_{2}, \\
\dot{e}_{3}= & -\left(\beta+\Delta_{4}\right) e_{3}-\left(\beta+\Delta_{4}-b-\Delta_{2}\right) x_{3}+e_{1} e_{2} \\
& +e_{1} x_{2}+x_{1} e_{2}+V_{3}, \\
\dot{e}_{4}= & -k x_{1}-k e_{1}-0.3 e_{2} e_{3}-0.3 x_{3} e_{2}-0.3 x_{2} e_{3} \\
& -0.3 x_{2} x_{3}+V_{4} .
\end{aligned}
$$

In order to solve the finite-time master-slave synchronization problem between system equations (15) and (16), we select the Lyapunov function:

$$
V=\frac{1}{2} e_{1}^{2}+\frac{1}{2} e_{2}^{2}+\frac{1}{2} e_{3}^{2}+\frac{1}{2} e_{4}^{2}
$$

Differentiation of this function with respect to time yields

$$
\dot{V}=e_{1} \dot{e}_{1}+e_{2} \dot{e}_{2}+e_{3} \dot{e}_{3}+e_{4} \dot{e}_{4}
$$

Combining (18) and (20), we have

$$
\begin{aligned}
\dot{V} & =e_{1}\left(\alpha\left(e_{2}-e_{1}\right)+(\alpha-a)\left(x_{2}-x_{1}\right)+V_{1}\right) \\
& +e_{2}\left(\left(\gamma+\Delta_{3}\right) e_{1}+\left(\gamma+\Delta_{3}-c-\Delta_{1}\right) x_{1}-e_{2}\right. \\
& \left.-e_{1} e_{3}-e_{1} x_{3}-x_{1} e_{3}+y_{4}+V_{2}\right) \\
& +e_{3}\left(-\left(\beta+\Delta_{4}\right) e_{3}-\left(\beta+\Delta_{4}-b-\Delta_{2}\right) x_{3}+e_{1} e_{2}\right. \\
& \left.+e_{1} x_{2}+x_{1} e_{2}+V_{3}\right)+e_{4}\left(-k x_{1}-k e_{1}-0.3 e_{2} e_{3}\right. \\
& \left.-0.3 x_{3} e_{2}-0.3 x_{2} e_{3}-0.3 x_{2} x_{3}+V_{4}\right) .
\end{aligned}
$$

We defined the active control functions $V_{1}(t), V_{2}(t), V_{3}(t)$, and $V_{4}(t)$ as follows:

$$
\begin{aligned}
V_{1}= & -(\alpha-a)\left(x_{2}-x_{1}\right)-\alpha e_{2}-\left|e_{1}\right|^{m} \operatorname{sign}\left(e_{1}\right) \\
V_{2}= & -\gamma e_{1}-(\gamma-c) x_{1}-y_{4}+e_{1} x_{3}-k_{1}\left|x_{1}\right| \operatorname{sign}\left(e_{2}\right) \\
& -k_{2}\left|e_{1}\right| \operatorname{sign}\left(e_{2}\right)-\left|e_{2}\right|^{m} \operatorname{sign}\left(e_{2}\right) \\
V_{3}= & -e_{1} x_{2}+(\beta-b) x_{3}-k_{3}\left|x_{3}\right| \operatorname{sign}\left(e_{3}\right) \\
& -\left|e_{3}\right|^{m} \operatorname{sign}\left(e_{3}\right) \\
V_{4}= & k x_{1}+k e_{1}+0.3 e_{2} e_{3}+0.3 e_{2} x_{3}+0.3 e_{3} x_{2} \\
& +0.3 x_{2} x_{3}-\left|e_{4}\right|^{m} \operatorname{sign}\left(e_{4}\right) .
\end{aligned}
$$

One obtains

$$
\begin{aligned}
\dot{V}= & -\alpha e_{1}^{2}-\left|e_{1}\right|^{1+m}+\Delta_{3} e_{1} e_{2}+\left(\Delta_{3}-\Delta_{1}\right) x_{1} e_{2}-e_{2}^{2} \\
& -k_{1}\left|x_{1}\right| e_{2} \operatorname{sign}\left(e_{2}\right)-k_{2}\left|e_{1}\right| e_{2} \operatorname{sign}\left(e_{2}\right) \\
& -\left|e_{2}\right|^{1+m}-\left(\beta+\Delta_{4}\right) e_{3}^{2}+\left(\Delta_{2}-\Delta_{4}\right) x_{3} e_{3} \\
& -k_{3}\left|x_{3}\right| e_{3} \operatorname{sign}\left(e_{3}\right)-\left|e_{3}\right|^{1+m}-\left|e_{4}\right|^{1+m} \\
= & -\alpha e_{1}^{2}-\left[k_{2}-\Delta_{3} \operatorname{sign}\left(e_{1} e_{2}\right)\right]\left|e_{1} e_{2}\right| \\
& -\left[k_{1}-\left(\Delta_{3}-\Delta_{1}\right) \operatorname{sign}\left(x_{1} e_{2}\right)\right]\left|x_{1} e_{2}\right| \\
& -\left(\beta+\Delta_{4}\right) e_{3}^{2} \\
& -\left[k_{3}-\left(\Delta_{2}-\Delta_{4}\right) \operatorname{sign}\left(x_{3} e_{3}\right)\right]\left|e_{3} x_{3}\right|-\left|e_{1}\right|^{1+m} \\
& -\left|e_{2}\right|^{1+m}-\left|e_{3}\right|^{1+m}-\left|e_{4}\right|^{1+m} \\
\leq & -\left|e_{1}\right|^{1+m}-\left|e_{2}\right|^{1+m}-\left|e_{3}\right|^{1+m}-\left|e_{4}\right|^{1+m} \\
= & -2^{(1+m) / 2} V^{(1+m) / 2} .
\end{aligned}
$$

From Lemma 1, it follows that (18) is finite-time stabilized. Thus, uncertain slave system (16) can synchronize uncertain master system (15) in finite time.

Theorem 3. Suppose that $k>0,0<m<1$. Let controller $u_{i}(i=1,2,3,4)$ be defined as (22). Then uncertain slave system (16) synchronizes with uncertain master system (15) in finite time.

\section{Numerical Simulations}

4.1. Case of the Certain Parameters. To verify the effectiveness of the proposed finite-time synchronization method, the 4 th-order Runge-Kutta algorithm is used to solve the sets of differential equations in connection with the master and slave systems. The initial values of the two systems are taken as $\left(x_{1}(0), x_{2}(0), x_{3}(0)\right)=(0.2,0.1,0.1)$, $\left(y_{1}(0), y_{2}(0), y_{3}(0), y_{4}(0)\right)=(4,4,4,4)$, and the simulation parameters are $a=10, b=-8 / 3, c=28$ and $k=2$, $\alpha=10, \beta=8 / 3$, and $\gamma=28$. The error variables of system (4) and system (3) are shown in Figure 1. The error vector is achieved as zero, which implies that system (3) and system (4) have achieved finite-time synchronization. It is clear that synchronization time of the state variables is $t_{1 s}=1.94935 \mathrm{~S}$, $t_{2 s}=1.94935 \mathrm{~S}, t_{1 s}=1.97484 \mathrm{~S}, t_{3 s}=1.9748 \mathrm{~S}$, and $t_{1 s}=2 \mathrm{~S}$, respectively. These results are in line with $t_{s}=\left|e_{0}\right|^{1-m} / k(1-$ $m)$. Figure 2 shows the synchronization of the Lorenz systems with the certain parameters.

4.2. Case of the Uncertain Parameters. In this subsection, we give numerical simulations to verify the results of Section 3.2. We choose the initial conditions of master system (15) and controlled slave system (16) as follows: $x_{0}=[3,5,5], y_{0}=$ $[100,130,110,140]$, and the uncertain parameters of master system and slave system are adopted as $\Delta_{1}=0.5 \sin t, \Delta_{2}=$ $0.5 \cos t, \Delta_{3}=0.1, \Delta_{2}=\cos t, m=1 / 2, k_{1}=0.8$, 

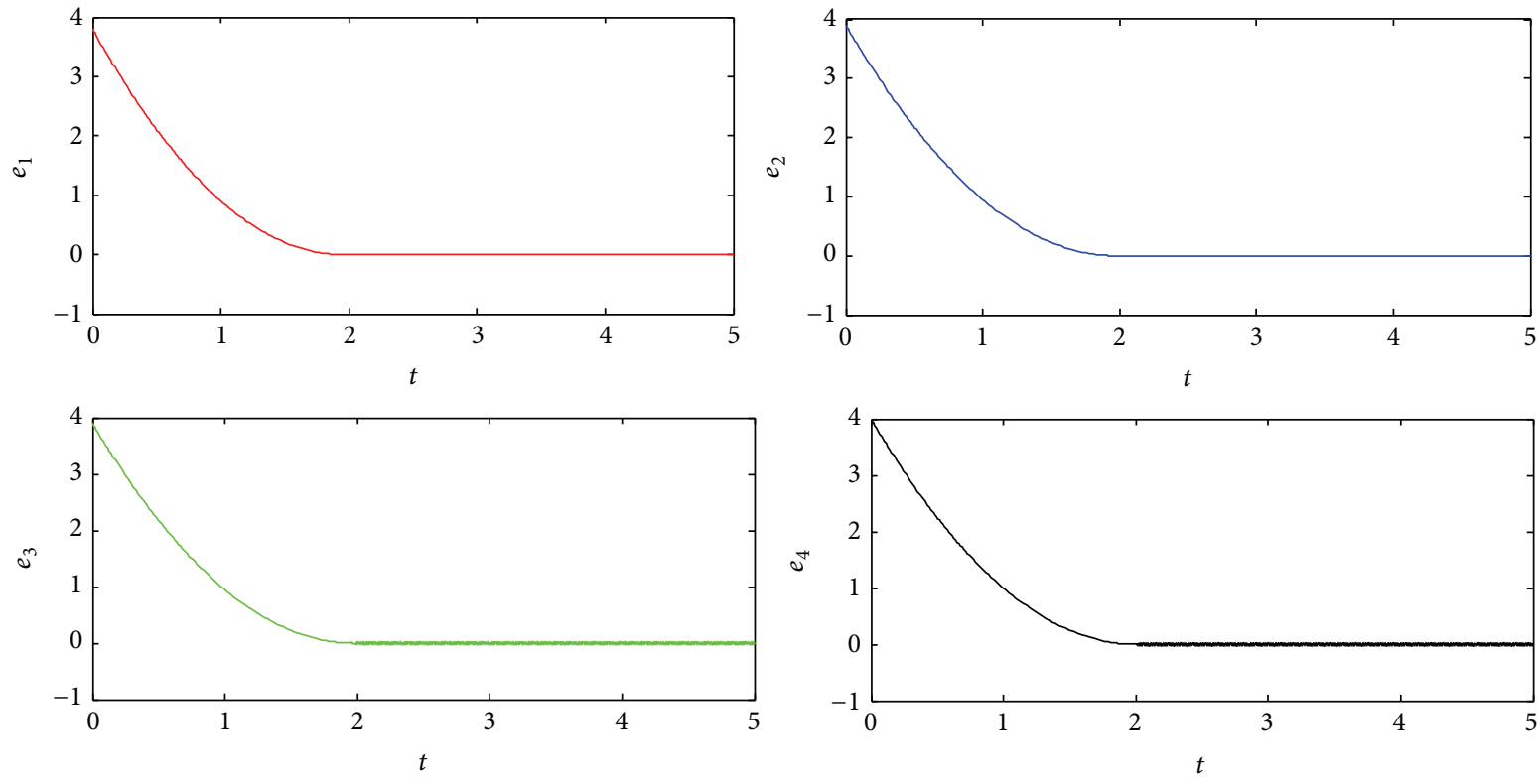

FIgURE 1: The error between system (3) and system (4).
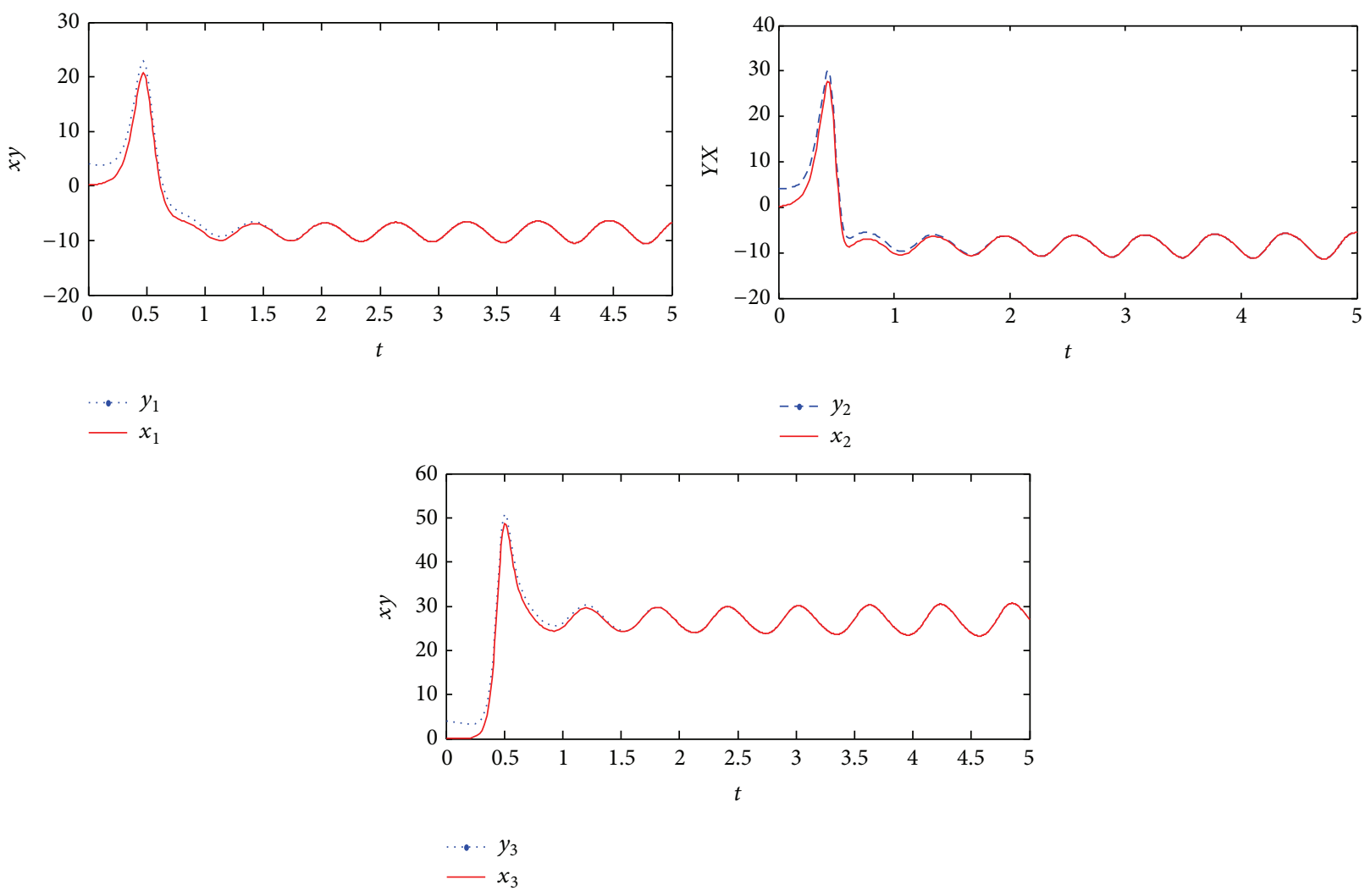

FIgURE 2: The state variables of system (3) and system (4).

$k_{2}=0.5$, and $k_{3}=2$. The simulation results are given in Figures 3-6, and the master system and the slave system achieve synchronization at a finite time. Figure 6 shows clearly that the synchronization errors converge to zero very quickly.

\section{Design of Circuit}

5.1. Case of the Certain Parameters. Because the values of the state variables are out of the scope of the amplifier, the linear compressor of the system variable is necessary; to be specific, 


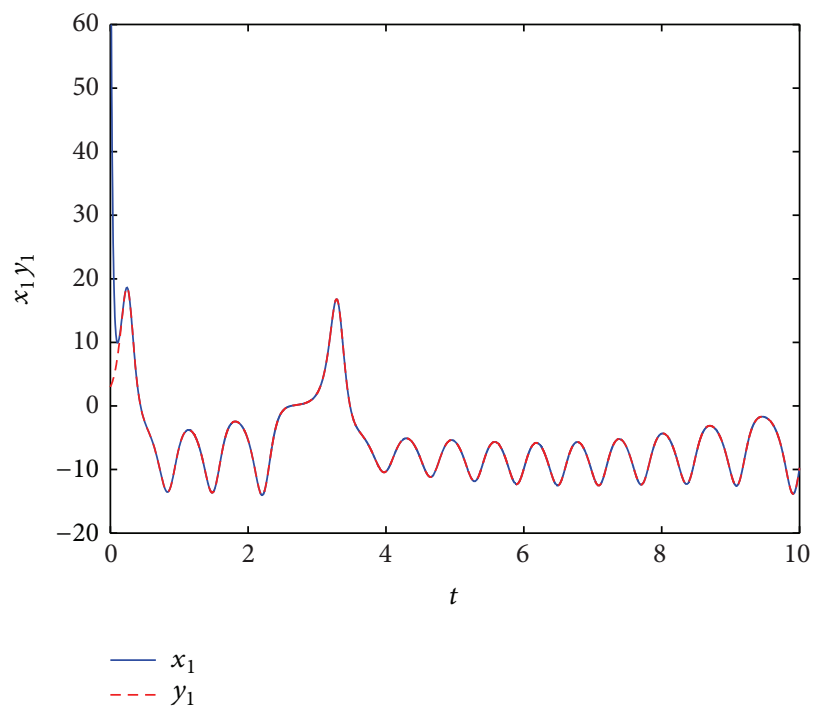

FIgURE 3: State trajectories of the uncertain master $x_{1}$ and slave system $y_{1}$.

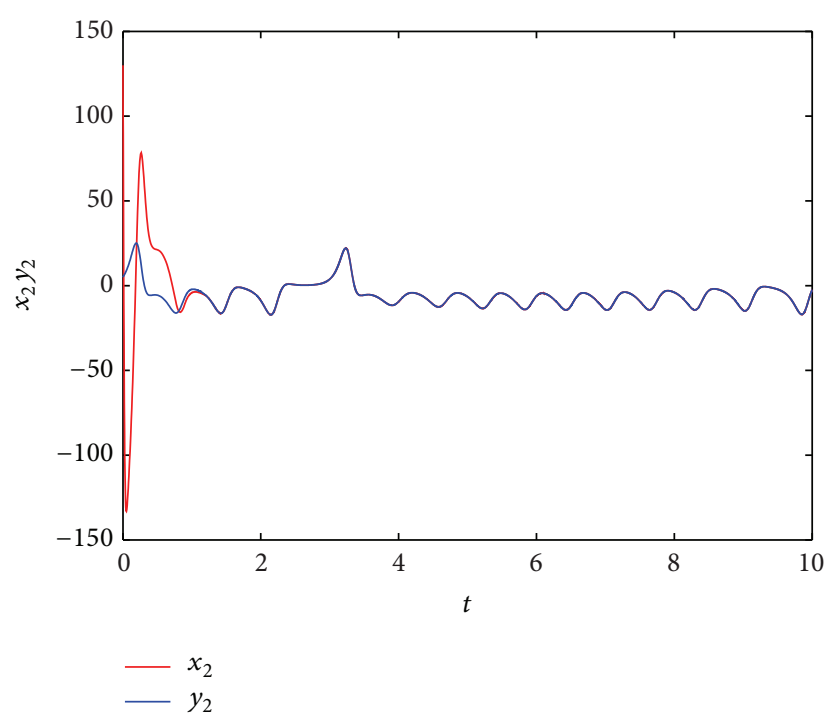

FIGURE 4: State trajectories of the uncertain master $x_{2}$ and slave system $y_{2}$.

variables of system are multiplied by a factor $\zeta=0.1$ [17]. The transform has no influence on the dynamics of the system, so the circuit equation of the master system can be written as

$$
\begin{aligned}
\frac{d x_{1}}{d t} & =\frac{1}{\zeta c_{1} R_{2}} x_{2}-\frac{1}{\zeta c_{1} R_{4}} x_{1}, \\
\frac{d x_{2}}{d t} & =\frac{1}{\zeta c_{2} R_{6}} x_{1}-\frac{1}{\zeta c_{2} R_{9}} x_{2}-\frac{1}{\zeta c_{2} R_{7}} x_{1} x_{3}, \\
\frac{d x_{3}}{d t} & =\frac{1}{\zeta c_{3} R_{11}} x_{2} x_{3}-\frac{1}{\zeta c_{3} R_{12}} x_{3} .
\end{aligned}
$$

Compared with system equation (3), we can obtain, $1 / \zeta c_{1} R_{2}=$ $1 / \zeta c_{1} R_{4}=10,1 / \zeta c_{2} R_{6}=28,1 / \zeta c_{2} R_{9}=1,1 / \zeta c_{3} R_{11}=$

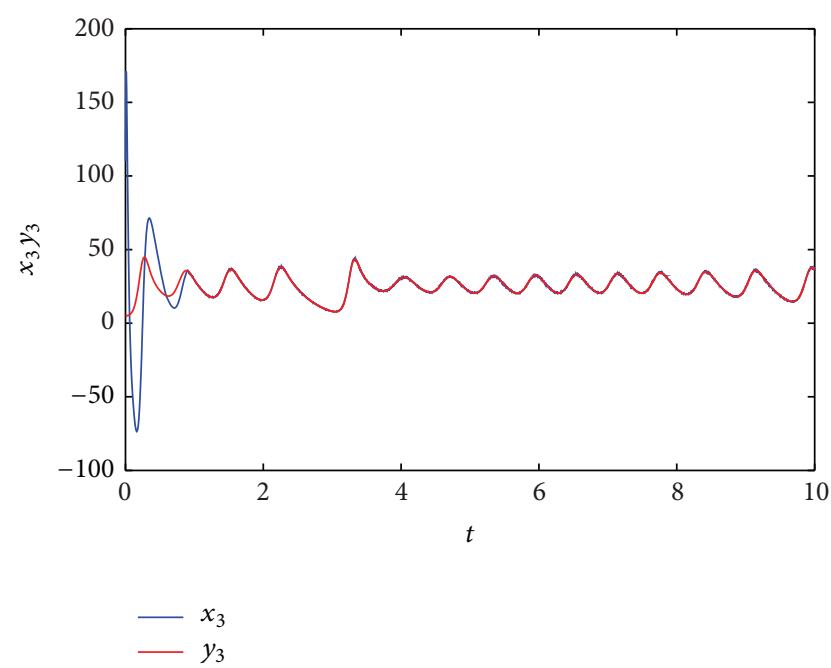

FIGURE 5: State trajectories of the uncertain master $x_{3}$ and slave system $y_{3}$.

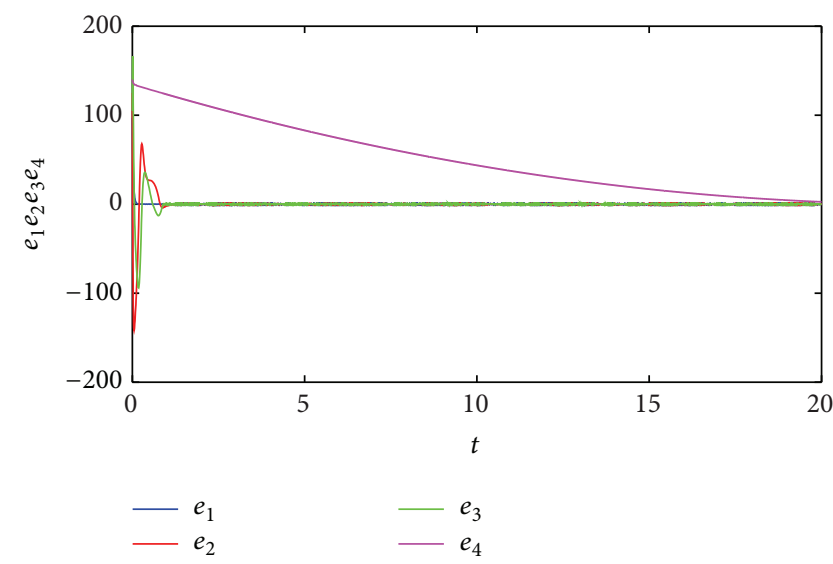

FiguRE 6: Synchronization errors of uncertain Lorenz system. 


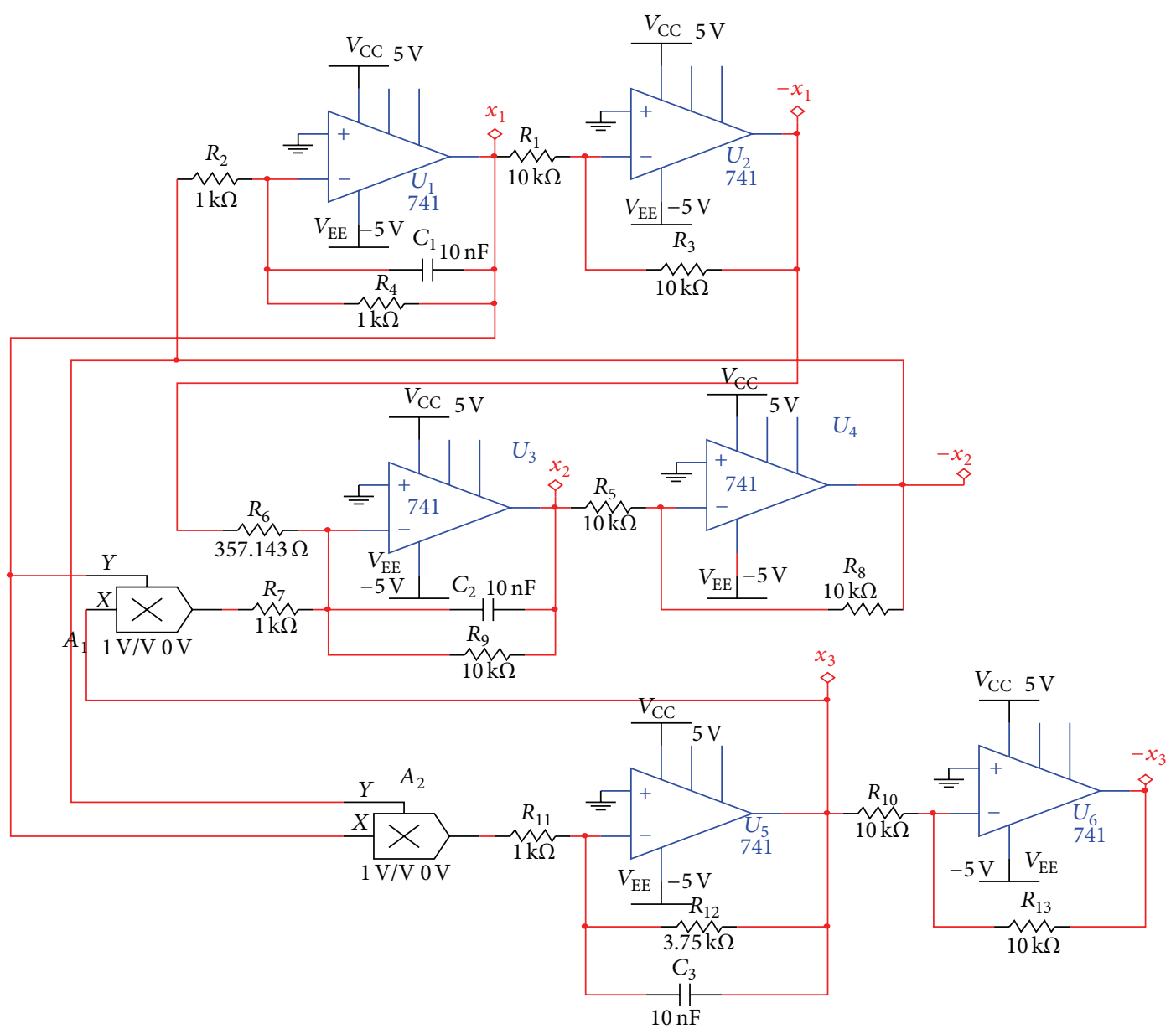

FIgURE 7: The circuit of the master system.

$1 / \zeta_{2} R_{7}=1$, and $1 / \zeta_{3} R_{12}=8 / 3$. From here we have different values of the components $R_{2}=R_{4}=R_{7}=R_{11}=1 \mathrm{~K} \Omega$, $R_{1}=R_{3}=R_{5}=R_{8}=R_{10}=10 \mathrm{~K} \Omega, R_{6}=357.143 \mathrm{~K} \Omega$, $R_{12}=3.57 \mathrm{~K} \Omega$, and $C_{1}=C_{2}=C_{3}=C_{4}=10 \mathrm{nF}$.

As shown in Figure 7, we have reduced the number of circuits and further reduced the design complexity of system circuit. The operational amplifiers LM741 and associated circuitry perform the basic implementation of addition, subtraction, and integration. The nonlinear terms of system are implemented with the analog multipliers AD633.

For the slave system, we take the same design as the master system. The circuit equation of system (4) can be written as follows:

$$
\begin{aligned}
\frac{d y_{1}}{d t} & =\frac{1}{\xi_{4} R_{14}} y_{2}-\frac{1}{\xi_{c_{4}} R_{15}} y_{1}, \\
\frac{d y_{2}}{d t} & =\frac{1}{\xi_{c_{5} R_{22}}} y_{1}-\frac{1}{\xi_{c_{5} R_{21}}} y_{2}-\frac{1}{\xi_{c_{5} R_{23}}} y_{1} y_{3}, \\
\frac{d y_{3}}{d t} & =\frac{1}{\xi_{c_{6} R_{26}}} y_{1} y_{2}-\frac{1}{\xi_{6} R_{28}} y_{3}, \\
\frac{d y_{4}}{d t} & =0 .
\end{aligned}
$$

Slave circuit is implemented via operational amplifiers. $u_{16 \mathrm{~A}}$ constitutes a subtractor circuit, with $y_{i}$ minus $x_{i}$ and voltage comparator LM339DG implement sign operational. Average absolute value detector circuit consists of $u_{16 B}, u_{16 C}$, and others. Root circuit consists of $u_{17 \mathrm{~A}}$ and $A_{5}$. When the parameters $k=0.5$ and $m=0.5$, we can get the value of the component:

$$
\begin{aligned}
\frac{1}{\xi c_{4} R_{14}} & =\frac{1}{\xi c_{4} R_{15}}=10, \\
\frac{1}{\xi c_{5} R_{22}} & =28, \\
n \frac{1}{\xi_{c_{5}} R_{21}} & =1, \\
\frac{1}{\xi_{c_{5}} R_{23}} & =1, \\
\frac{1}{\xi_{c_{6}} R_{26}} & =1, \\
\frac{1}{\xi c_{6} R_{28}} & =\frac{8}{3}, \\
R_{14} & =R_{15}=R_{23}=R_{26}=1 \mathrm{~K} \Omega,
\end{aligned}
$$




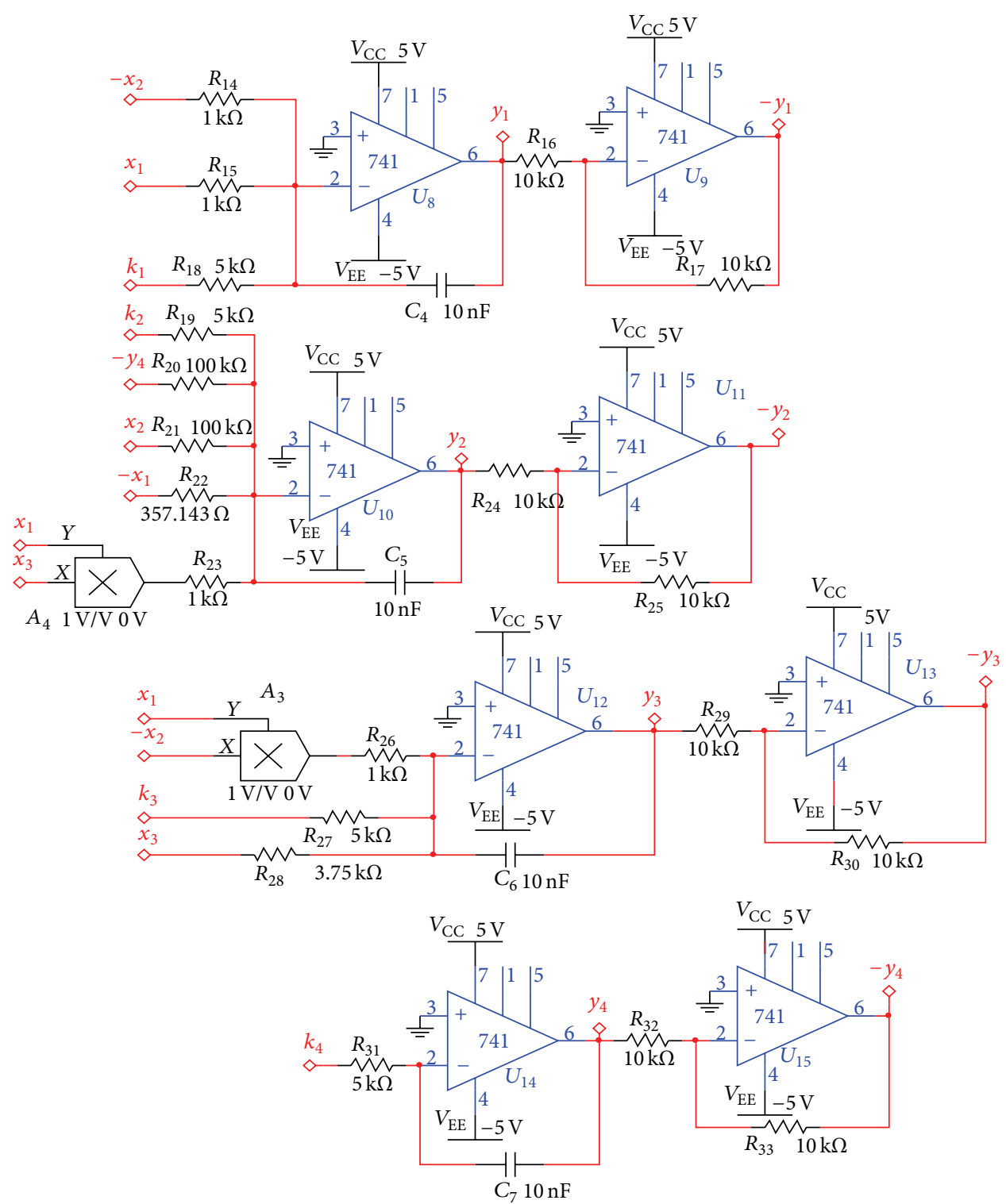

FIGURE 8: The circuit of slave system.

$$
\begin{aligned}
R_{16} & =R_{17}=R_{24}=R_{25}=R_{29}=R_{30}=R_{32}=R_{33} \\
& =10 \mathrm{~K} \Omega, \\
R_{20} & =R_{21}=100 \mathrm{~K} \Omega, \\
R_{22} & =357.14 \mathrm{~K} \Omega, \\
R_{28} & =3.75 \mathrm{~K} \Omega, \\
R_{18} & =R_{19}=R_{27}=R_{31}=5 \mathrm{~K} \Omega, \\
C_{4} & =C_{5}=C_{6}=C_{7}=10 \mathrm{nF},
\end{aligned}
$$

and Figure 8 shows the circuit diagram of the slave system.
The circuit of the control function $u$ consists of subtractor circuit, sign function circuit, average absolute value detector circuit, and root circuit. By adjusting the value of the $R_{i}(i=$ $18,19,27,31)$, the master system and the slaver system can realize the synchronization quickly and monotonically through controller circuits. The circuit of the control function is shown in Figure 9. The result of the simulation is shown in Figure 10. It can see that the ratio of $y_{i}: x_{i}(i=1,2,3)$ is in close proximity to $1: 1$, which shows that the master system and the slaver system are synchronized.

5.2. Case of the Uncertain Parameters. In this subsection, combining with the numerical simulations of the Section 4.2, master system (15) is implemented in Figure 11. Figure 11 shows the circuit diagram of the master system and the values 


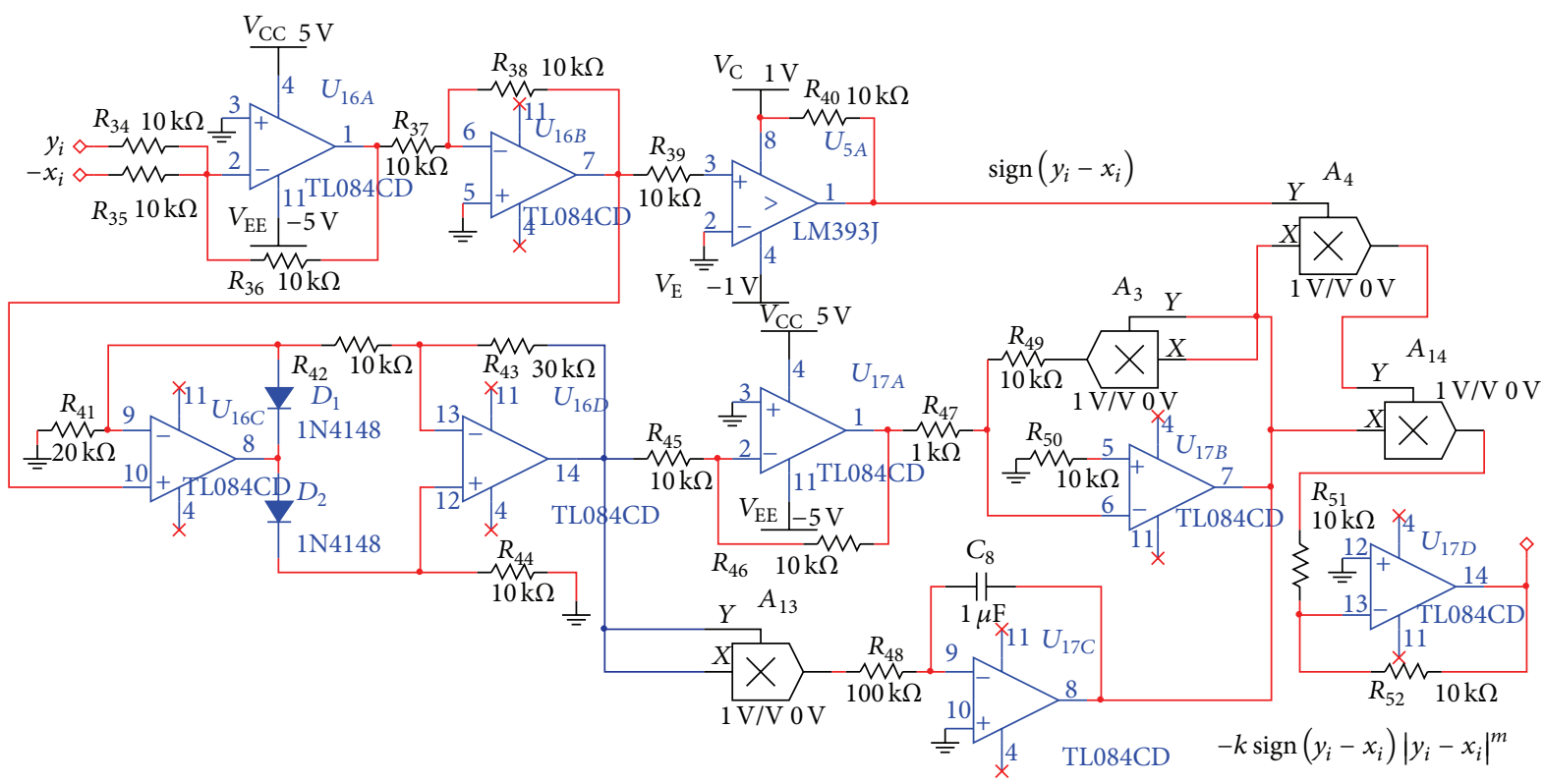

FIGURE 9: Function circuit.
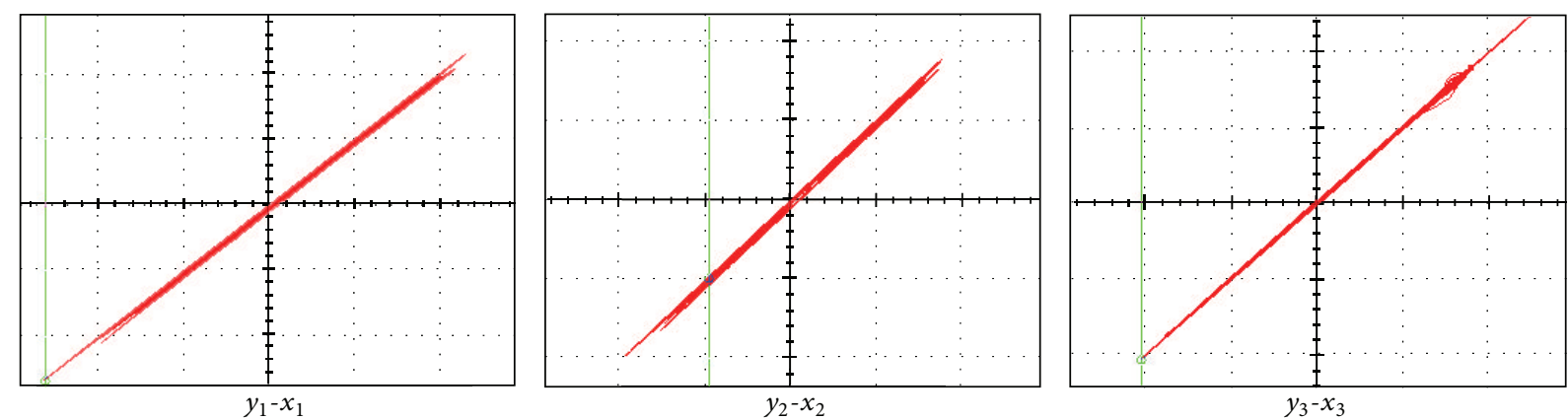

Figure 10: The ratio of the state variables of different systems.

of the circuit components; the frequency of the sinusoidal signal is $2000 \mathrm{~Hz}$.

Figure 12 shows the circuit diagram of the state variables for slave system (16). The value of the components in Figures 11 and 12 are scaled by a factor 0.1 .

The circuit schematic is composed of four submodule control circuit. Figure 13 shows the circuit diagram of control function $V_{2}$, and the design methods of the other circuit is identical to it. Figure 14 illustrates the synchronization is achieved between master system (15) and slave system (16).

\section{Experiment on Secure Communication}

Most secure communication schemes using chaotic dynamics are based on identical synchronization. These systems employing chaos are partly due to their high unpredictability and simplicity of implementation. Chaotic Masking (CM), Chaos Shift Keying (CSK), Chaos On-Off Keying (COOK), and Differential Chaos Shift Keying (DCSK) are the most common chaos modulation techniques. However, the technology of the finite-time synchronization and unpredictability of uncertain parameters can enhance the security of communication. In the paper, based on the method of finitetime synchronization, simulation test of the digital secure communication adopting Chaotic Masking (CM) technology is performed. The information signal $s_{T}(t)$ is chosen, which is a square signal with frequency of $4 \mathrm{khz}$ and $500 \mathrm{mVp}$. The signal is modulated with the variable of the master system. When $x_{1}(t)$ is chosen as a marking signal, the transmitting system can be written as

$$
\begin{aligned}
& \dot{x}_{1}(t)=a\left(x_{2}(t)-x_{1}(t)\right)+s_{T}(t), \\
& \dot{x}_{2}(t)=c x_{1}(t)-x_{2}(t)-x_{1}(t) x_{3}(t), \\
& \dot{x}_{3}(t)=x_{1}(t) x_{2}(t)-b x_{3}(t)
\end{aligned}
$$




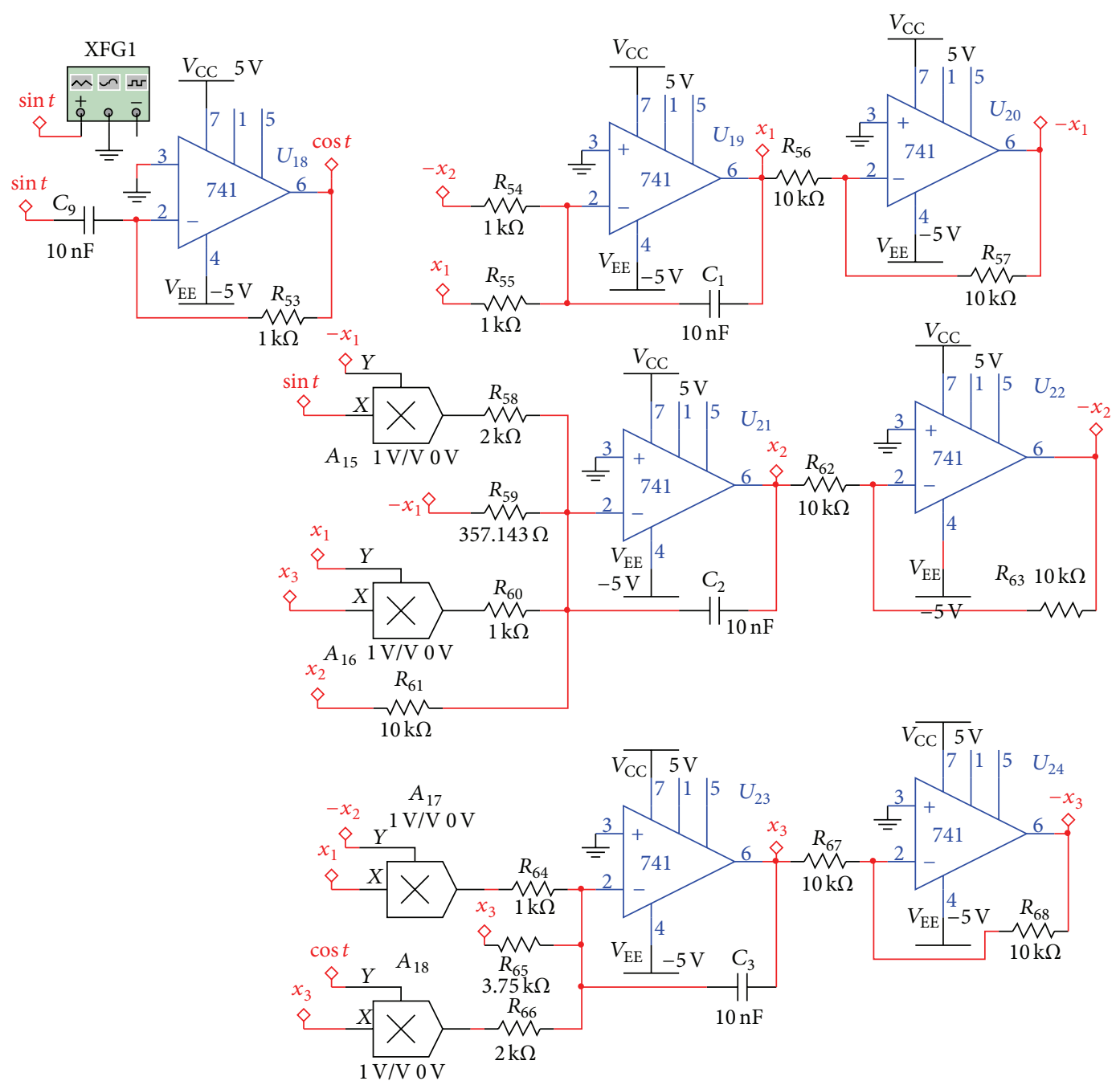

FIGURE 11: Circuit of the master system with uncertain parameters.

The receiving system is written as

$$
\begin{aligned}
& \dot{y}_{1}(t)=\alpha\left(y_{2}(t)-y_{1}(t)\right)+u_{1}, \\
& \dot{y}_{2}(t)=\gamma y_{1}(t)-y_{2}(t)-y_{2}(t) y_{3}(t)+y_{4}(t)+u_{2}, \\
& \dot{y}_{3}(t)=-\beta y_{3}(t)+y_{1}(t) y_{2}(t)+u_{3}, \\
& \dot{y}_{4}(t)=-k y_{1}(t)-0.3 y_{2}(t) y_{3}(t)+u_{4} .
\end{aligned}
$$

At the transmitter, the information signal $s_{T}(t)$ is added into the master system and chaos signal mask the information signal. One obtained the encryption signal:

$$
x^{\prime}(t)=x_{1}(t)+s_{T}(t)
$$

At the receive end, for maintaining synchronization between $y_{1}(t)$ and $x_{1}(t)$, the information signal $s_{R}(t)$ is decoded by a subtractor:

$$
\begin{aligned}
s_{R}(t) & =x^{\prime}(t)-y_{1}(t)=x_{1}(t)+s_{T}(t)-y_{1}(t) \\
& =s_{T}(t) .
\end{aligned}
$$

Modulation-demodulation of the chaotic communication system is shown in Figure 15.

The result of circuit simulation proves that the encryption signal $s^{\prime}(t)$ has chaotic characteristics and contains information. The synchronous demodulation signal $s_{R}(t)$ is consistent with the modulating signal $s_{T}(t)$ after the finite time $t_{s}$; Figure 16 shows the waves of the signals and state variables of the system. Chaos communication system showed good reducibility.

\section{Conclusion}

In this paper, the finite-time chaos synchronization between the $3 \mathrm{D}$ Lorenz system and the $4 \mathrm{D}$ hyperchaotic system is investigated. We proposed an accurate finite-time synchronization control strategy and implemented finite-time synchronization between the 3D Lorenz system and the $4 \mathrm{D}$ hyperchaotic system based on the finite-time stability theory. An electronic circuit is designed to realize the controller 


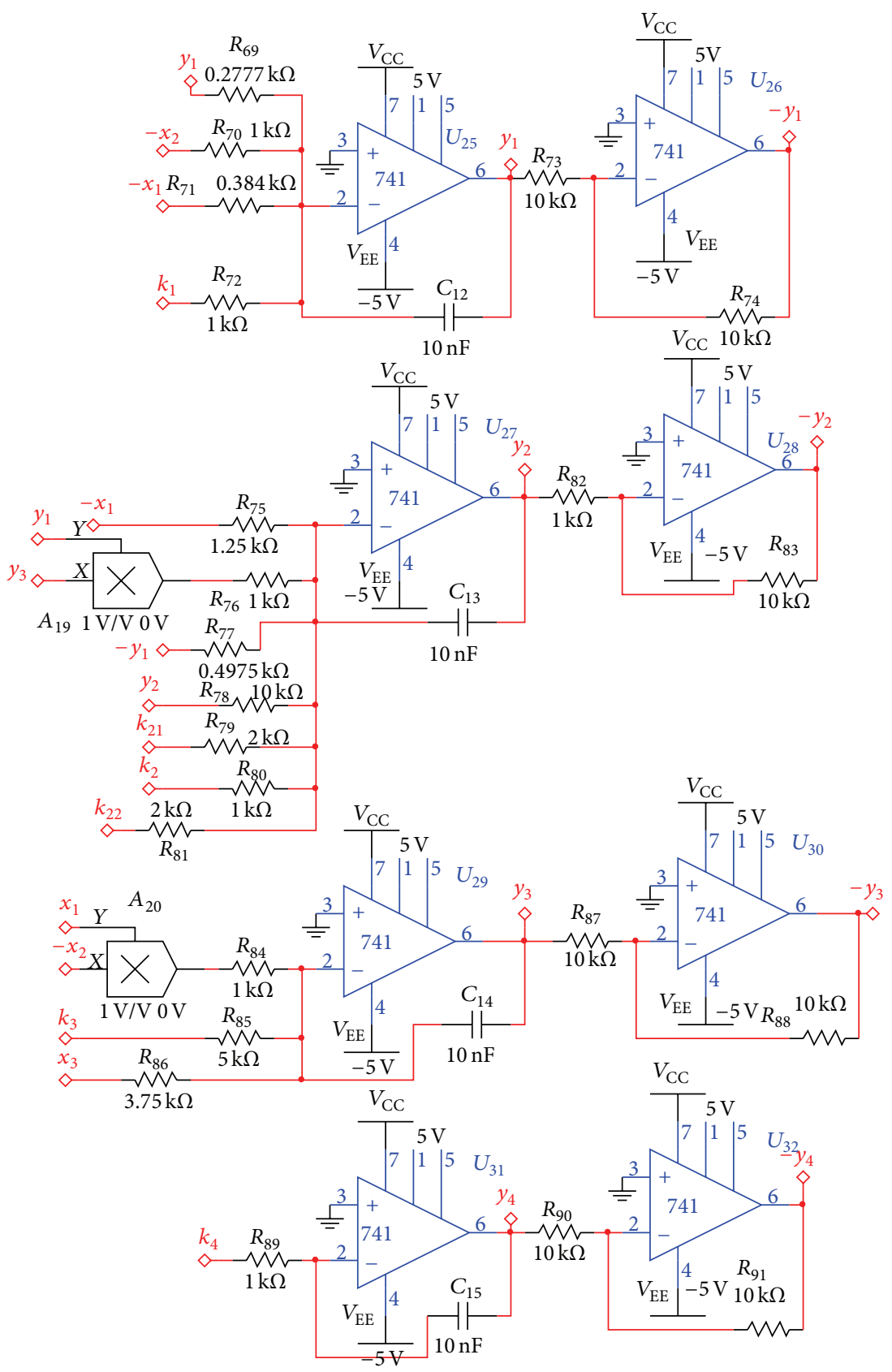

FIGURE 12: Circuit of the slave system with uncertain parameters.

using Multisim 12. Numerical simulations have verified the effectiveness of these methods. Furthermore, the experimental results are in agreement with numerical simulation results and demonstrate the effectiveness and feasibility of the proposed method.

\section{Competing Interests}

The authors declare that they have no competing interests.

\section{Acknowledgments}

This work was partly supported by the Scientific Research Foundation of the Higher Education Institutions of Guangxi Province of China (Grants nos. KY2015ZD098, KY2016YB364), the University Key Teachers Training Program from Guangxi Higher Education Institutions of China (Document no. [2014]39), the Scientific Research Foundation (Grant no. 2013YJZD02), and the Special Foundation of Excellent Talents (Grant no. G20140003) in Yulin Normal University. 


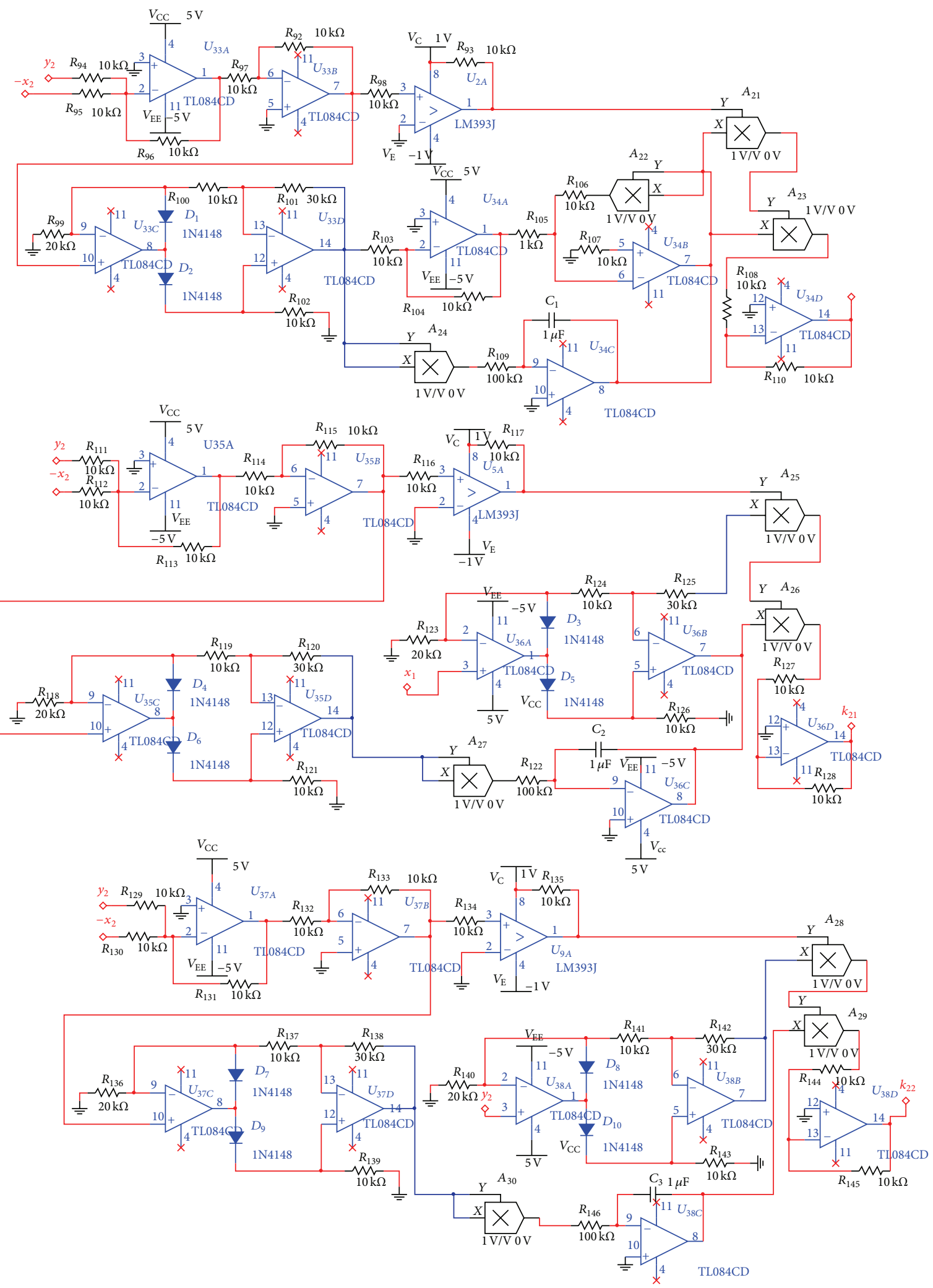

FIgURE 13: Circuit diagram of the control function $V_{2}$. 

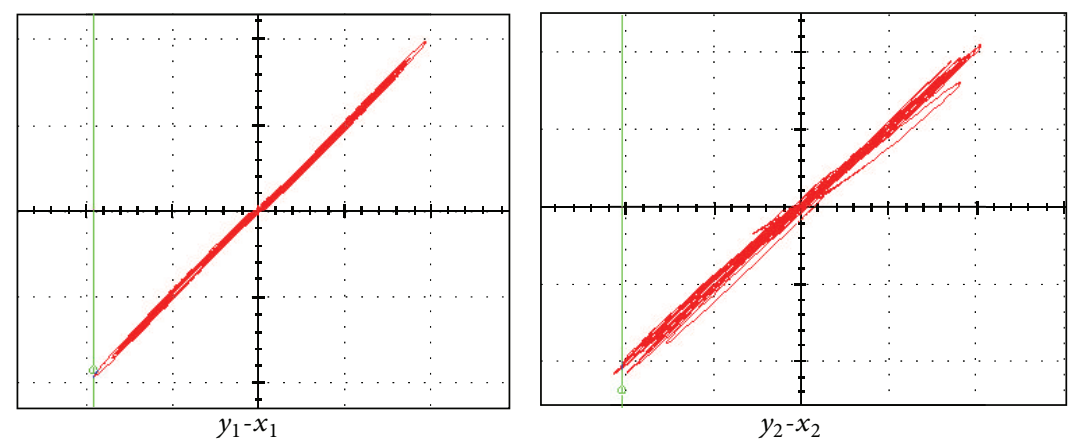

FiguRE 14: The ratio of the state variables of different systems.
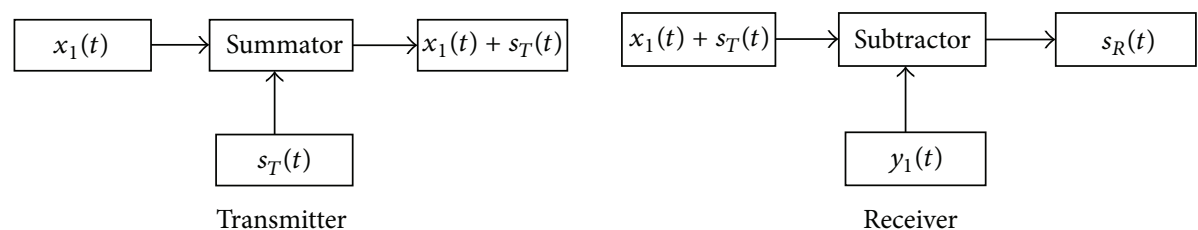

FIGURE 15: Chaotic communication system.

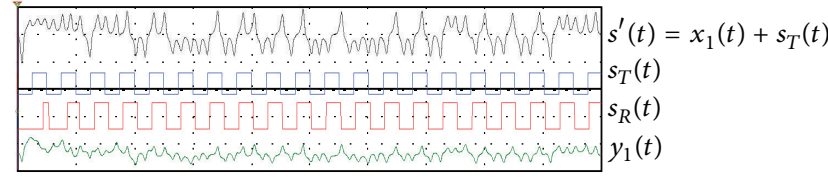

FIGURE 16: The simulation result of secure communication.

\section{References}

[1] L. M. Pecora and T. L. Carroll, "Synchronization in chaotic systems," Physical Review Letters, vol. 64, no. 8, pp. 821-824, 1990.

[2] T. Yang and L. O. Chua, "Impulsive stabilization for control and synchronization of chaotic systems: theory and application to secure communication," IEEE Transactions on Circuits and Systems I: Fundamental Theory and Applications, vol. 44, no. 10, pp. 976-988, 1997.

[3] B. Blasius, A. Huppert, and L. Stone, "Complex dynamics and phase synchronization in spatially extended ecological systems," Nature, vol. 399, no. 6734, pp. 354-359, 1999.

[4] Y. Mao, W. Tang, Y. Liu, and L. Kocarev, "Identification of biological neurons using adaptive observers," Cognitive Processing, vol. 10, no. 1, pp. 41-53, 2009.

[5] D. W. Graham, C. W. Knapp, E. S. Van Vleck, K. Bloor, T. B. Lane, and C. E. Graham, "Experimental demonstration of chaotic instability in biological nitrification," ISME Journal, vol. 1, no. 5, pp. 385-393, 2007.

[6] S. Bowong and J. Kurths, "Parameter estimation based synchronization for an epidemic model with application to tuberculosis in Cameroon," Physics Letters, Section A: General, Atomic and Solid State Physics, vol. 374, no. 44, pp. 4496-4505, 2010.

[7] Q. Zhang, J. Luo, and L. Wan, "Parameter identification and synchronization of uncertain general complex networks via adaptive-impulsive control," Nonlinear Dynamics, vol. 71, no. 12, pp. 353-359, 2013.
[8] Q. Zhang, J. Luo, and L. Wan, "Erratum to: parameter identification and synchronization of uncertain general complex networks via adaptive-impulsive control," Nonlinear Dynamics, vol. 75, no. 1, pp. 403-405, 2014.

[9] C. Zeng, Q. Yang, and J. Wang, "Chaos and mixed synchronization of a new fractional-order system with one saddle and two stable node-foci," Nonlinear Dynamics, vol. 65 , no. 4, pp. $457-$ 466, 2011.

[10] S. Li and Y.-P. Tian, "Finite time synchronization of chaotic systems," Chaos, Solitons and Fractals, vol.15, no. 2, pp. 303-310, 2003.

[11] X.-D. Xia, W.-L. Yang, and S.-W. Zheng, "Finite time synchronization of sprott circuits with uncertain parameters," in Proceedings of the International Conference on Advanced Computer Control (ICACC '09), pp. 693-696, Singapore, January 2009.

[12] Y. Feng, L. Sun, and X. Yu, "Finite time synchronization of chaotic systems with unmatched uncertainties," in Proceedings of the 30th Annual Conference of the IEEE Industrial Electronics Society, pp. 2911-2916, Busan, Republic of Korea, November 2004.

[13] H. Wang, Z. Han, Q. Xie, and W. Zhang, "Finite-time chaos synchronization of unified chaotic system with uncertain parameters," Communications in Nonlinear Science and Numerical Simulation, vol. 14, pp. 2239-2247, 2009.

[14] M. Haeri, M. S. Tavazoei, and M. R. Naseh, "Synchronization of uncertain chaotic systems using active sliding mode control," Chaos, Solitons \& Fractals, vol. 33, no. 4, pp. 1230-1239, 2007.

[15] S. P. Bhat and D. S. Bernstein, "Continuous finite-time stabilization of the translational and rotational double integrators," IEEE Transactions on Automatic Control, vol. 43, no. 5, pp. 678-682, 1998.

[16] S. Ding, S. Li, and Q. Li, "Stability analysis for a second-order continuous finite-time control system subject to a disturbance," Journal of Control Theory and Applications, vol. 7, no. 3, pp. 271276, 2009. 
[17] Y. Hong, J. Huang, and $\mathrm{Y} . \mathrm{Xu}$, "On an output feedback finitetime stabilization problem," IEEE Transactions on Automatic Control, vol. 46, no. 2, pp. 305-309, 2001.

[18] S. Pang, Y. Liu, and C. Zhu, "Circuit implementation and application of hyperchaotic Lorenz system," Computer Engineering and Applications, vol. 49, pp. 235-239, 2013. 


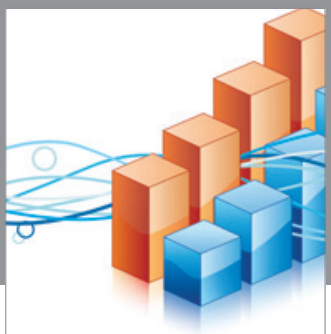

Advances in

Operations Research

vatem alat4

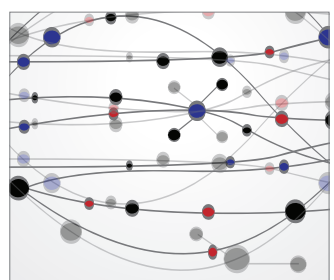

\section{The Scientific} World Journal
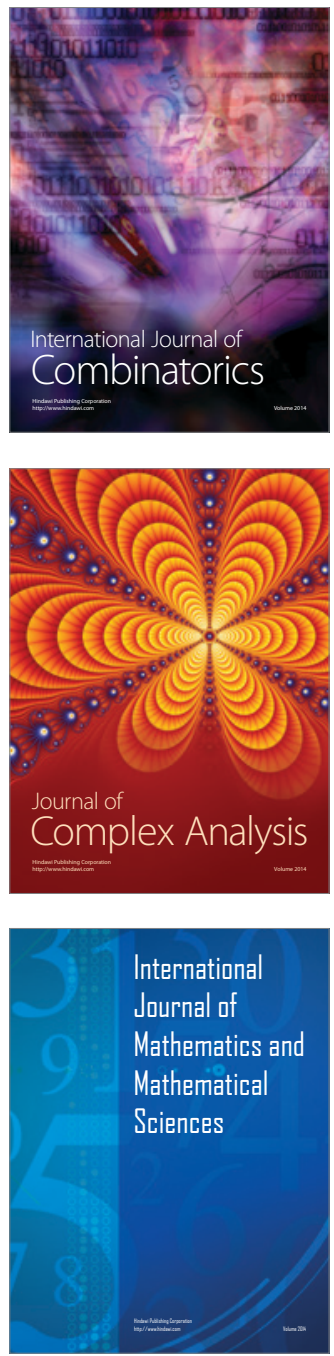
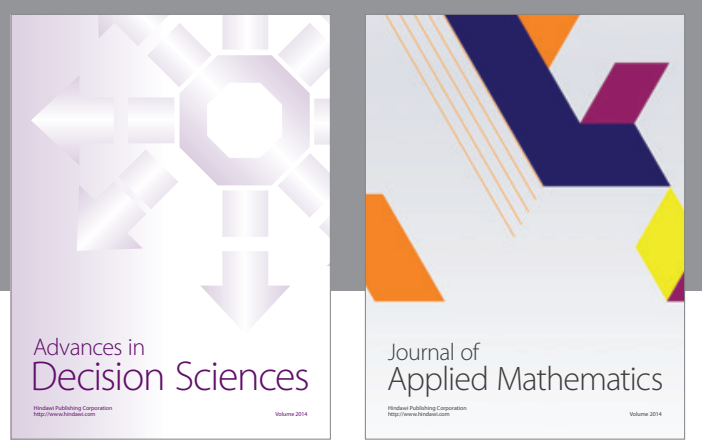

Algebra

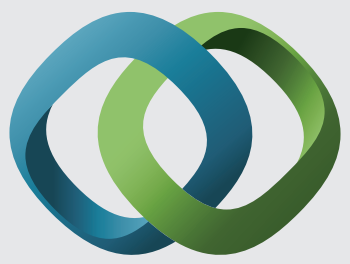

\section{Hindawi}

Submit your manuscripts at

http://www.hindawi.com
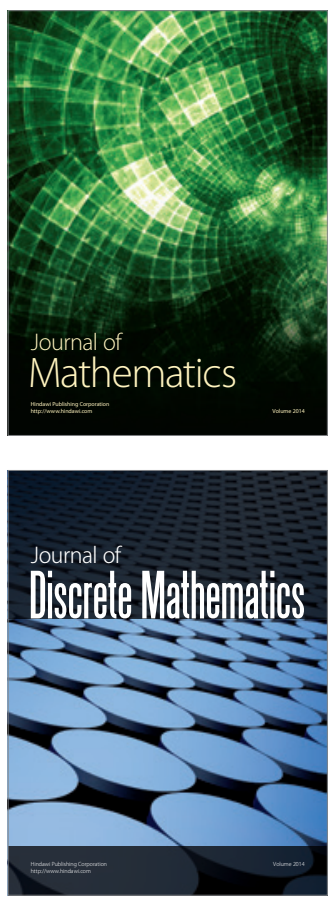

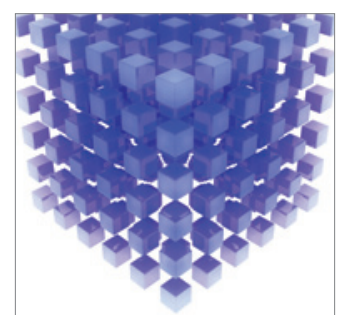

Mathematical Problems in Engineering
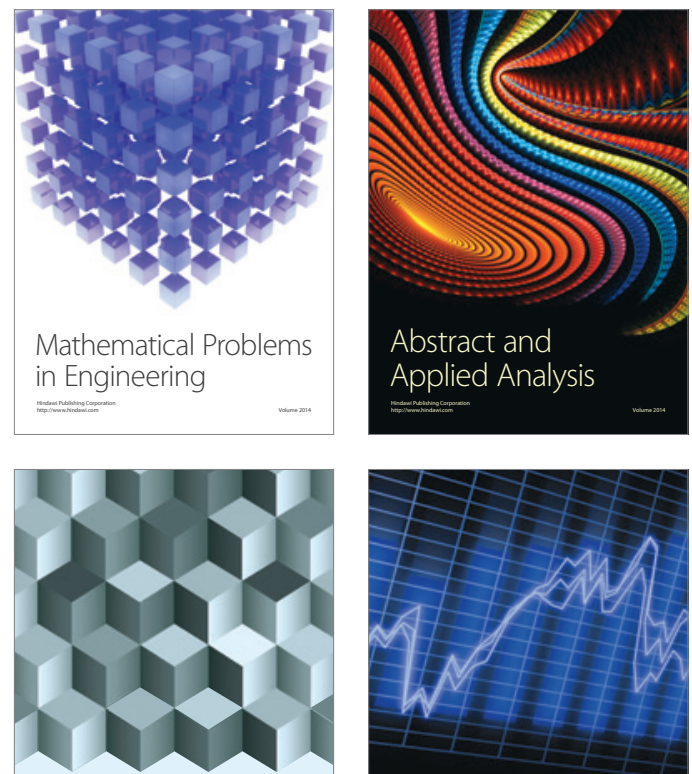

Journal of

Function Spaces

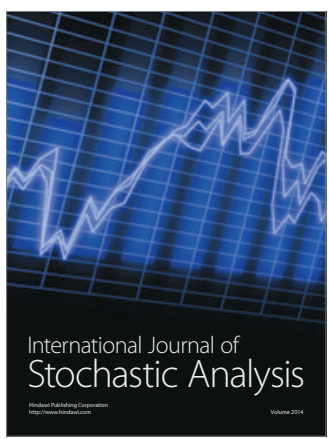

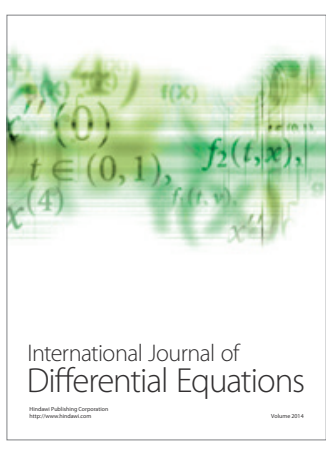
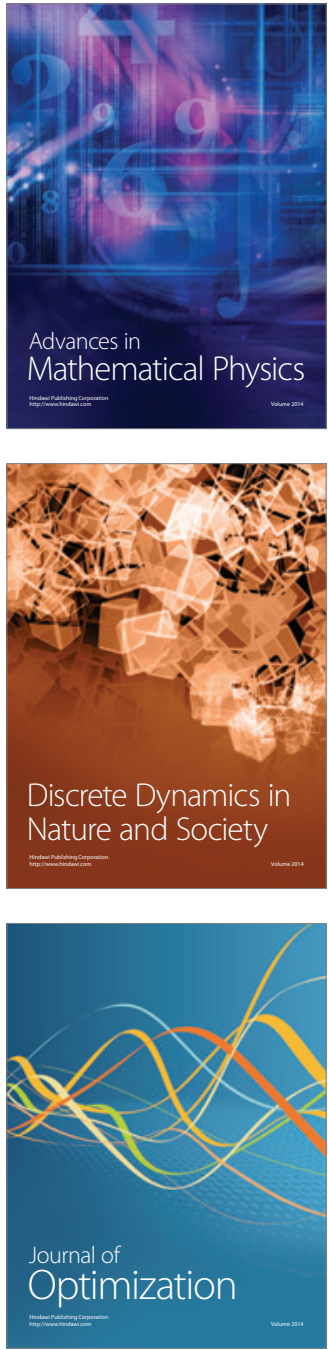